\title{
The Role of Philosophy in the University
}

\author{
Thomas A. F. Kelly
}

\section{What is Pbilosopby?}

Iris Murdoch once remarked that, "to do philosophy is to explore one's own temperament, and yet at the same time to attempt to discover the truth'. ${ }^{1}$ Elsewhere, Murdoch talks about a necessary tension within the discipline:

It is sometimes said, either irritably or with a certain satisfaction, that philosophy makes no progress. It is certainly true, and I think this is an abiding and not a regrettable characteristic of the discipline, that philosophy has in a sense to keep trying to return to the beginning: a thing which it is not at all easy to do. There is a two-way movement in philosophy, a movement towards the building of elaborate theories, and a move back again towards the consideration of simple and obvious facts. McTaggart says that time is unreal, Moore replies that he has just had his breakfast. Both these aspects of philosophy are necessary to it. ${ }^{2}$

To explore one's own temperament and to try to discover the truth; to keep in mind the simple and the obvious and to construct necessarily ever more elaborate explanations: there is a rhythm of expansion and return which is vital to philosophy, a kind of respiration which must endure, despite philosophy's many transformations during its long career. Murdoch presents a partial view of that respiration of philosophy, a return by philosophy to basics even as it stretches out towards a complete, articulate understanding, insofar as this is possible.

Philosophy must keep both of these impulses together as one repeated rhythmic figure. There is a certain sense in which what philosophy studies is not in the least esoteric or recondite: it raises systematically questions and issues which arise spontaneously for the limited, vulnerable, that is, incarnate, consciousness which I am and we are, and for which my own existence is opaque. Indeed, philosophy may be seen as the necessary outgrowth of that incarnation and opacity. The opacity calls for light: 'know thyself' was the watehword philosophy inherited from the Delphic Oracle via Socrates, and to know oneself, in particular individuality as well as in terms of one's place in real and conceptual contexts, is still the philosophical vocation. Let us look more closely at this theme.

Philosophy is impossible for animals, which are prelinguistic in that they cannot ask 'why?' or 'whither?', and for Divinity, which can only be self-transparently as its own why. Philosophy is the necessary outgrowth of the human's neither being divine nor merely animal, but being a kind of existence between these two estates. ${ }^{3}$

Heidegger called this 'between' Dasein, existence, engaged reality, and he noted that its fundamental nature was to be a kind of being for which its own being is an issue. ${ }^{4}$ To be human is not to be a fixed and self-enclosed 'thing'-indeed there is nothing which is that, even though that mistaken picture has an allure-it is to be a process of a certain kind, namely a self-directive, freely self-realising, process. Self-directive, yet not completely; free, yet not absolutely; self-realising, but always carrying within it the surd of the given. 
This is the earth from which all philosophy grows, and its object is this unending questionability of our existence, its why and its whither. Far from being a disembodied Cartesian observer, Dasein is a being essentially incarnate in the world, one which can realise itself only in and through its necessary relations to the people and things with which it is confronted in the world.

Philosophy is therefore concerned with $m y$ decisions and their basis, $m y$ place within the human as well as the natural world. I decide how to be, I decide what I am to be. I decide how I shall spend the essentially limited capital which is my time, my duration of existence. I am circumscribed by death, the possibility which cancels all my other possibilities, and am constrained also by the-social, cultural, somatic, physical in the broadest sense-geography which I cannot choose but in which I already find myself.

Yet within this limited space I can make something of myself, and this expression has more literal weight then we might at first suspect. The situation, the geography in which I find myself demands that I choose. To choose is inseparable from making real one of the potentialities, mine and of my world, which belong to me as the entity I am, at this precise moment and place in the process which is my existence: $I$ am in and of the world and what I do affects it. The future exists in the present as a set of rays of diverse potentiality, each ray a possible world, originating at the present moment. Choice helps to make actual one of those possibilities, though it is not the only actualising factor.

To make real one potential is to reject others which are incompatible with it, and which will therefore never be realised. All such choice is a choice of self-what shall I be?-but a se]f which is essentially related and relational, never other than in a world with other selves and things. So, the question as to which is the more worthwhile possibility of being is an inescapable one. That it is possible to spend my limited possibilities wastefully-a literal waste of self, for myself and for others who are involved with me-and that I could have done other than I did, that I am therefore free, are the issues which give choice its drama, its sharpness.

One of the finest presentations of the drama of choice is to be found in the Confessions of Augustine. The story really concerns the identity of Augustine, who Augustine is, who Augustine is to be, and this identity is not a simple or univocal relation of sameness between states: identity embraces quite radical change. The narrative tells of the rejection by Augustine of a false self or selves in favour of what he finds to be his best possibility of being, which he embraces as his true self. All other selves were false precisely as embodying less of the good than that embodied by the chosen self. We can imagine an Augustine who never converted, his great inteliectual and emotional powers as he grew older poisoning him and those with whom he was intimate, his natural tendencies towards rage, vanity and manipulation coming to the fore. Or we can imagine an Augustine who converted later or earlier than did the actual Augustine. But these counterfactual Augustines are counterfactual due to the choices actually made by Augustine, within the constraints of his existential geography. He chose to $b e$, he chose a potentiality of his identity for the greatest good, and became the Augustine we now know, and to know whom was a benefit to those others who were his friends, making actual a world in which he became the teacher-friend par excellence to many, aiding them in their own quest for the realisation of themselves in the good..$^{5}$ 


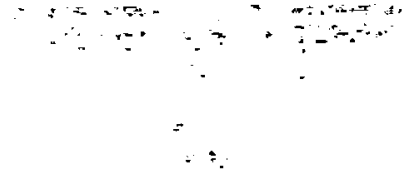

To choose is to choose under the behest of the good, for the sake of the good, in virtue of the attraction of the good. Otherwise, there is no real choice but caprice or sheer randomness, To be free is to be able to choose for the sake of the good. In this way, 'goodness', 'choice', 'freedom' 'constraint', 'self' and 'other' are rubrics for the issues which arise necessarily and spontaneously for each and every human being, and they form the necessary content of any discourse which can yield understanding of this human predicament. I underline that without the possibility of such discourse, the specifically human would disappear into animality-whose being 'dumb' consists precisely in this absence-and the exercise of what freedom humans have, and to which this discourse is necessary, would become impossible.

Such issues emerge in the life of every individual and are handled by him or her, each in his or her own way, precisely because human beings are irreducibly individual. Although it might be said that we are all identical in one way or another, since the predicate ' $x$ is human' means the same thing every time it is correctly applied, the tissue of the predicate is open, so that it is quasi-analogical, and not strictly univocal. We ought, perhaps, to think of the predicate as being like a complex formula with very many variables; abstract in relation to the dense particularity of the real which it tries-and fails-definitively to express, but able in its systematic unclarity, its fuzziness, to embrace such diverse interpretations of what it is to be human as those supplied by, say, Stalin or Saint Therese of Lisieux. To inhabit the world, to live, is to be obliged to choose, and therefore to be obliged to search for the enlightenment which enables choice. This is what it is to 'explore one's own temperament', or, to attempt to follow the Socratic dictum: 'know thyself.

But as soon as we begin to raise such questions, the impulse exists to understand as deeply as possible, to question systematically, to compare our experiences with those of others, to shine a light though ignorance and forgetfulness, to make explicit what is implicit, to construct a theory, or simply, to talk. Construct a theory? The notion of theory tends to have a bad reputation today, tending to suggest a kind of escapism, although the movement to theory and the notion of theory itself need only be construed as the impulse towards the richest, most adequate and comprehensive and nuanced understanding possible, which is more like the connotation of the Greek theoria, which is at bottom a seeing, a view of things as they really are. An eminently clear, and indeed, a noble example of this drive, is, I think, the following:

Speculative Philosophy is the endeavour to frame a coherent, logical, necessary system of general ideas in terms of which every element of our experience can be interpreted. By this notion of 'interpretation' I mean that everything of which we are conscious, as enjoyed, perceived, willed, or thought, shall have the character of a particular instance of the general scheme. Thus the philosophical scheme should be coherent, logical and, in respect to its interpretation, applicable and adequate. Here 'applicable' means that some items of experience are thus interpretable, and 'adequate' means that there are no items incapable of such interpretation. ${ }^{6}$

To engage in this kind of project is inevitably to move away from the immediately concrete, which for some philosophers is already a fault. Other philosophers, nurtured on the contemporary French distrust of grands récits, might see in it a kind of tyranny or violence, the kind associated with the project of Hegel, which seems to many to 
involve the maiming of reality-usually vulnerable human reality ${ }^{7} \rightarrow$ on the procrustean bed of absolute knowledge. Such charges cannot be levelled against the philosopher whom I have just quoted, A. N. Whitehead, whose overtly 'speculative' philosophy inspires thinkers whose thought is - as was Whitehead's-concemed with the preservation of the environment and with sustainable living, with human rights and dignity, and with the common good, and who, like Whitehead himself, not only reject all violence, tyranny and injustice, but actively struggle against these evils. ${ }^{8}$

But if the history of philosophy, the history that is, of such 'speculative' attempts, teaches us anything, it is that an 'absolute' philosophy, an unsurpassable theory which is finally comprehensive, is impossible. As Goedel pointed out in another context, there can be no complete and coherent system, which embraces all truth. A Hegel will inevitably be followed by a Kierkegaard, the reaching out to heaven by a return to the earth. A genuine philosophy such as that of Whitehead, as opposed to an ideology or systematic distortion of reality, therefore must embody both; philosophy must breathe. Recall Murdoch: 'it is sometimes said, either irritably or with a certain satisfaction, that philosophy makes no progress. It is certainly true, and ... this is an abiding and not a regrettable characteristic of the discipline'; philosophy must try to be, and will inevitably fail to be, comprehensive and complete.

But how are we to conceive philosophy, if not as a breaker's yard of wrecked systems, outmoded even as they were built? How do we avoid falling into a deadening - and logically untenable - relativism, which tells us that what's true for you is true for you and what's true for me is true for me, and thus acts as the reductio ad absurdum of all our efforts?

The answer lies in the fact that philosophy happens as conversation. Schools and theories are not churches, and do not, and cannot, demand exclusive allegiance. Truth is revealed as ruling value precisely as that which alone is worthy of our allegiance, and which stands not as already attained, but as to be attained, as the goal and meaning of our intellectual striving. But to say that is to say (if we say truly) that we are already in partial possession of it, for we can even now utter true sentences-if we could not, truth would be shut off from us. Moreover, the fact of having access to true propositions here and now, though this truth is de facto limited by ignorance and falsity, demands the overstepping of those barriers, towards ever greater truth, which is asymptotically approached. At no point can we hope for the absolute anmulation of ignorance and falsity, a state which is forever beyond the human situation, which is inconceivable without these limits. Even the most adequate possible account of, say, an historical period, or the course of evolution in a given geological epoch, must remain in ignorance of a vast amount of data which are irretrievably lost, must miss the particularity, the full and unique history of the inhabitants of such epochs, whether animal or human. Even in something as small-scale as a family history, much that was once known is lost at the death of an elderly relative, certainly their first-person perspective on events. In this, philosophy is no different from any other discipline: at no point can we imagine the last scientist or historian laying down the pen and saying that their discipline is now complete-after a Newton there is also an Einstein.

Truth is a value and an only asymptotically attainable goal; it is a nice reflection that, just as the asymptote cuts the line at infinity though it draws ever closer to it, knowledge and reality are only realised coterminously, if they ever are, in the Divine. 
Without the presupposition of truth, however asymptotically we must approach it, there is mere difference of viewpoints, but no possibility of improvement, and we are back in the frictionless nullity of relativism. ${ }^{10}$ We move along the curve towards that infinitely distant identity by dialogue, by the confrontation of perspectivally divergent view-points. Murdoch perceptively describes Hegel, who is often cast in the role of absolutising villain, as the "philosopher who, while not being the greatest, contains possibly more truth than any other ${ }^{1}{ }^{1}$ More truth, but not the absolute and final word. This makes of Hegel a worthwhile dialogue partner who has much to teach us. Our appropriation of his thought must necessarily involve a process of mutual correction, and this is the reality of dialogue, in which alone we can hope, insofar as this is possible, to participate in truth, to have our ignorance overcome and our misconceptions revealed for what they are.

This is recognised by Plato who almost always casts phitosophy explicitly as dialogue, and as an exploration of the possibilities given in dialogue. Insofar as we are alone, our ignorance and delusion are left unchallenged; in dialogue we participate in truth, and can have access to an ever-less-distorted view of the world and of our place in it, a view necessary to our decision-making. The Cartesian-style thinker, who believes it possible to attain truth se solum alloquendo consigns himself to the permanence of unhealed distortion and ignorance in his thought, a state from which the instinct for truth of the historical Descartes - as opposed to his conceptual persona in the Meditations-rescued him. ${ }^{12}$ Truth can only ever be ours and never mine; a 'truth' which is in principle mine and not yours, is delusion. ${ }^{13}$

This makes philosophy the democratic 'public space' par excellence, for the search for truth consists in the conscientious contributions of all the partners over time. John Henry Newman gives a masterly delineation the kind of epistemic virtues which are necessary to the discovery of truth when he writes in the Grammar of Assent:

We have arrived at these conclusions-not ex opere operato, by a scientific necessity independent of ourselves--but by the action of our own minds, by our own individual perception of the truth in question, under a sense of duty to those conclusions and with an intellectual conscientiousness. ${ }^{14}$

All inquiry, as Newman well understood, is co-constituted by ethical and logical principles. He well understood also the life and historical evolution of understanding, which we have been discussing. Here is his brilliant and suggestive sketch of the same theme, from his work the Essay on Development-and from the idea's point of view!

being the germination, growth, and perfection of some living...truth, in the minds of men during a sufficient period... Its development then is not like a mathematical theorem worked out on paper, in which each successive advance is a pure evolution from a foregoing, but it is carried on through individuals and bodies of men; it employs their minds as instruments, and depends upon them while it uses them. ...It grows when it incorporates; and its purity consists not in isolation, but in its continuity and sovereignty. ${ }^{13}$

Newman is above all a philosopher of the organic and concrete; in the above passage he shows his grasp of the contingent steps in the evolution of an idea, of some moment of understanding. It evolves not predictably like a theorem, but by combining 
the diverse and contingent contributions of 'individuals and bodies of men', conscientious individual participants each with his or her own unique perception of the truth in question; its identity consists not in 'isolation', in failing to incorporate, to 'prehend', to use Whitehead's pregnant expression, within it the reality of other ideas, but in 'continuity and sovereignty'.

If then, truth can only be participated in through dialogue, it becomes the task of the philosopher to understand this dialogue, to make the ethico-logical principles which constitute it, and their work within it, visible. Some philosophers have in recent years taken on this task. A seminal contribution in this regard is Karl-Otto Apel's essay, 'The a priori of the Communication Community and the Foundations of Ethics: the Problem of a Rational Foundation of Ethics in the Scientific Age', in which Apel ably demonstrates the interwovenness of ethics and logic in all rational life. In response to the Kantian question of whether the Devil can be a logician--that is, the question of whether or not an evil will can make use of logic as a value-neutral tool in the pursuit of its evil ends-he writes as follows:

Pierce pointed out that truth, in the sense of the consensus postulate of the logic of science, cannot be attained by finite individuals and that, for this reason, membership of the argumentative community of scholars incorporates a basic transcendence of the egoism of finite beings-a kind of self-surrender in terms of 'logical socialism'. This means that the Devil, inasmuch as he desired to be a member of the community of argumentation would for ever more have to behave towards its members [so as to derive benefit from their undistorted contributions]... as if he had overcome egoism... This appears to indicate that the moral norm which is presupposed by the will to truth, and, therefore, by membership of the unlimited community of argumentation cannot be a 'hypothetical imperatjve'...The fact that the search for truth must also anticipate the morality of an ideal communication community when it presupposes intersubjective consensus will most probably reveal a modern analogue to the classical doctrine of the 'transcendentals'... The identity of unum, bonum and verum-must still be posited by the modern philosophy of a historically precarious mediation between theory and practice as a necessary postulate in terms of a critique of meaning and, with regard to its realization, as the 'principle of hope'. ${ }^{16}$

It is a notable lack in modern, and some contemporary, philosophy that there is little consideration of the degrees of intimacy an individual enjoys with others, a topic which was taken to be of the utmost importance in ancient and medieval thought, treated there under the heading of friendship. In Kant, despite the 'kingdom of ends' formulation of the Categorical Imperative, the moral agent tends to remain aloof and lonely, however rational the sovereign self may be. In Heidegger too, there is no real other. Perhaps it is in Lévinas's conception of the face of the other that we come closest in the contemporary period to the real presence of the other, as one who is a freedom beyond the closed circle of my intentions and enjoyments, and who as vulnerable, as suffering, relativises them. The rich man of the parable is not condemned because he goes out of his way to torture Lazarus, but because he simply steps over him, ignoring his suffering. The other is one who makes my ethical space our space, makes a we of an $l$, such that my good is not and cannot be disjoined from that of the other. My good must always in some measure be our good, and the good, 
which in ancient and medieval thought is called happiness, is the one in which all these goods are harmonised.

Thus, an understanding of the way in which our coming together in a just community can be achieved is an issue for philosophy, as well as the nature of that justice itself. Ethics segues into politics, the philosophical investigation of the nature of justice. Further themes which are disclosed as essential to this essentially shared medium of dialogue are: the nature of argument, how we validly draw conclusions, how we interpret, what it is to know; and each of these forms a relatively independent investigation within the complex discipline of philosophy, namely logic, hermeneutics and epistemology.

But this is not all. The note of freedom in our account so far, as well as the nature of the self, as subject or as inter-subject, are inescapable issues for philosophy. The freedom of the self is presupposed by all discourse, and any denial of it is inconsistent, at least as a performative contradiction, for the belief that our freedom is jllusory is equivalent to the claim that I must hold the belief whether it is true or not. The ineliminable intersubjectivity of the self is likewise a presupposition of all discourse, such that subjectivity is only possible as intersubjectivity. Yet, these issues are not self-evident, though they may be made transparent by analysis. This task, which takes us into the presuppositions of ethics and of the other investigations we have mentioned, shapes the discipline which is variously called philosophical psychology or philosophical anthropology, and consists in the delineation of the structures necessary to the free, ineluctably ethical intersubjectivity which we are, which Dasein consists in.

Moreover, if discourse and truth are to be themes for philosophical investigation, then the nature of language's relation to reality, language as mediating truth, must also be systematically investigated. If a realistic account of truth is one which commends itself as the most adequate account of the nature of truth, then it becomes evident that this is possible only if the categorial framework of language is identical to the architecture of reality. Logic can and must be used in the disengagement and disclosure of this categorial framework, which can be shown to consist in three items, namely, entity, property and relation. ${ }^{17}$ These lead on to further topics such as process-since 'entity' is equivalent, not just to 'thing', but to 'event'-and thereby the question of the nature of time, and that of causality, from which the nature of time is inseparable. To perform this investigation into 'what there is' is to engage in that branch of philosophy called 'ontology'. And it is here perhaps that we come closest to the kind of philosophy called 'speculative' by Whitehead.

And above these questions, and prompted by them, philosophy asks the one which was probably best formulated by Kant as: what may I hope? This, despite superficial appearances, seems to be identical to the Leibnizian question: why is there something rather than nothing? These, or if they are ultimately equivalent, this, is a 'transcendental' question in that it brings us up against the limits of human being, for this question englobes the whole of existence in its horizon, and asks for a why for everything, asks for a reason for a hope beyond hope, for an enlightenment essentially located beyond the human horizon. The history of philosophy shows very diverse mappings of the geography which supports this question. Modern approaches tend to deconstruet the question as question, placing the 'beyond the middle' which it intends 
in the realm of faith, or to seek a hope or a reason immanent in the geography, as subject to interruption and vulnerability as every other object in that landscape. The classical approaches, which are still discussed as viable options, find a vector of transcendence within rationality itself (Anselm), a vector which leads beyond the realm of limited perfection to 'that than which no greater can be thought', or to the unsayable, or find the insufficiency of the world for its own existence to be the occasion for the appearance of the term "God' (Aquinas) as that without which there would be nothing. This concem for ultimate human fate is what is called 'metaphysics', and as such betokens a going beyond the realm of the temporal, the condition of all possible experience, to the unsayable, to self-existent existence itself. Immanentist philosophy denies the possibility of metaphysics, but the decision made in that regard conditions all philosophical questioning-for the purview of metaphysics takes in all 'lower' questions-and modifies how we view all the topics investigated by philosophy.

In this way, even at its most seemingly abstract, philosophy returns to its beginning, to the soil from which it grows, but not as mere repetition; rather as envisaging that beginning anew, through the experience gained over the journey which I have attempted to describe. Such is the rhythm necessary to philosophy: philosophy is not linear, but circular.

\section{The Place of Philosophy in the University}

If the image of philosophy which I have been trying to explicate is accurate, then it has already become clear that philosophy is always and already a conversation partner of all other disciplines, in the sense of a mutually corrective encounter which leads in the direction of truth, securing the partners' conscientious contributions by coevally logical and ethical means. It will immediately be objected that philosophy has nothing to offer to quantum physics, say, which is a value-free empirical and theoretical inquiry into the nature of physical reality. This, however, is an inadequate response.

Admittedly, philosophy does not produce quantum-physical results, but it is erroneous to think that such a discipline exists outside the territory inhabited by philosophy. Every discipline, as rational enterprise, instantiates the logico-ethical, the dialogical, structure which we have attempted to sketch above. This is not just to say that logic provides the canon for valid argumentation. As ethico-logical enterprise, science requires the elucidation of those ethical principles which form and govern it and which assign it a place within the totality of human good. The necessity for this kind of investigation is witnessed more clearly in those branches of science which touch more obviously on human wellbeing, and are required to have overt canons of ethical procedure, but no branch of science, no branch of the acquisition of knowledge, can do without such investigation, otherwise, such an investigation would be, per impossibile, of neutral worth, with no place in the totality of good.

A scientist may ask such questions, systematically investigate them, and as such ceases for the moment to be a pure scientist, and becomes a philosopher-and experience reveals that this examination is best accomplished in an interdisciplinary manner. The same is clear with regard to the professions whose practice is inculcated in the university: their aims, and goals relative to overall human wellbeing are to be questioned systematically, and for this to be done adequately, it must be done in an interdisciplinary manner. I do not intend here to prescribe the manner and detail of the 
interaction between philosophy and a given discipline, or to examine a range of such disciplines to map where philosophical discourse is mandatory: the practice of these disciplines raises ethical questions with regard to their purpose, the kind of benefit which they confer, and 'best ethical practice' in their way of conducting themselves. Very often ethical questions bear on who loses and who wins, and what the nature of the loss is, and whether the win justifies it. A more radical way of putting it would be: who is to be hurt? A fruitful interdisciplinary collaboration is one in which such questions are allowed to appear in all their complexity, in the fullness of their content and scope; the kinds of responses to be given them decided a priori by neither side. In and through this collaboration, the particular principles which govern this particular area are gradually elucidated, and how those principles instantiate ineluctables such as 'do no harm', 'cause no innocent suffering', 'respect the dignity of persons', is revealed, thereby defining in greater clarity the meaning of the ineluctables. It could be said that all human life is an exploration of what the word 'good' (or 'true', and so on) means, and that history constitutes a maieutic, cultivating the good and true, and eliminating the bogus. Moral progress depends on this growth and on this elimination, for this process enables the gradual realisation of the good.

In all such dialogue, the stakeholders are not merely the practitioners of philosophy and its dialogue partner, but the whole of society whose good is being envisaged. And although, as we saw, such debate democratically mobilises all conscientious contributions and includes them in its evolution, there is a more profound principle of inclusion at work, such that the partners must explicitly represent the interests of all concerned persons - and this means everyone in society - especially those who have no voice, or who are excluded by incapacity from participation in the debate which affects their fate. A principle of universal concern is a dialogue-formative ineluctable.

This means also that such dialogue must try to forsee the effects of the progressive practice of the discipline in question on all members of society; in effect this means always mobilising the contributions of sociologists, anthropologists and other experts whose field of endeavour is the understanding of social processes and factors, within the debate, even when they are the partners of philosophy in critical dialogue towards ever-greater explicitness and self-awareness.

A principle of universal concern must posit each member of society as one of equal value with all others, and that this value must be progressively emancipated from the inevitable legacy of social distortion. The debate must always avail of the corrective supplied by the contributions of groups historically disempowered by such irrational distortions as racism, sexism, ageism, and the like. This is a kind of principle of vigilance which detects entrenched and emerging distortions of the ineluctable value of the individual. A principle of emancipation not only vindicates the value of the individual, but expresses this value in a system of rights, entitlements and duties belonging to full members of the community, a system which is itself under continued philosophical investigation and re-vision, with a view to an ever clearer perception of what rights, duties and entitlements there are, and what their particular justification is.

The study of philosophy encourages the appropriation by human beings of the resources with which their humanity is endowed, since philosophy attempts to be the clearest, most nuanced and most radical description of those resources; one might add that literature explores the same territory from a more concrete perspective, almost as 
though literature were an imaginative laboratory for the investigation of human possibility. It has been argued indeed that certain writers have been in advance of philosophers in their discoveries, and that only later did the philosophers catch up, Shakespeare and Tolstoy often being named in such arguments. History may be said to do the same, except its characters are real, and the study of history makes the present situation transparent as to its causes, those factors which determine or have determined the configuration of the present. However things may be in regard to the claims of individual disciplines, it is certainly true that the study of philosophy, literature and history have traditionally formed the basis of humanistic education, understood precisely as the emancipatory taking possession of the humanity that is revealed in these disciplines by individual human beings. Moreover there are none but practical arguments, of the 'how shall we manage the time-table?' variety, against, and many cogent arguments for, including such studies as secondary in the formation of scientists, and other practitioners of disciplines outside the hurnanities.

Each discipline is, moreover, in possession of what might be called 'regional ontologies', in that each deploys a categorial framework which deternines what the discipline recognises as real, and a value scheme as to the relative importance of such items. What is fragmented is unintelligible. If this principle is correct, then the ultimate intelligibility of the discipline is revealed only in bringing its regional ontology explicitly into the whole of discourse, the overall ontology which is investigated by philosophy. This is not to denigrate the relative independence (an absolute independence is incoherent) of the regional ontology, nor is it to suggest the colonisation of other disciplines by philosophy, but merely to recognise the analogical, as opposed to the equjvocal or univocal, nature of ontology, whose business it also is, besides investigating the categorial framework of discourse as such, to reconcile the differences without necessarily eliminating them, although in some cases this may be the logical course. The language of neuropsychology on the one hand, and first person narration, or talk within various disciplines (including philosophy itself) of notions like consciousness or motivation, on the other, might be an exampie of highly conflicted regional ontologies, one claiming the existence of certain entities such as intentions or the like, the other having no place for such items as genuine entities. The task of bringing these regional ontologies 'home' to some form of coherence within the totality of ontology proper is one in which philosophy is an indispensable, but not the only, participant.

In practice, all this means that philosophy must be available not only to students who have chosen this area as an avowed area of study, but that its various disciplines must be available as a secondary, but necessary, field of study for students in other disciplines: the decision as to which philosophical disciplines are most suitable to such students itself being undertaken by a process of dialogue between philosophers, the students in question, and the practitioners of the students' home discipline. For most, applied ethics will be a useful choice, as will logic, for some, courses in epistemology, hermeneutics, and even politics and ontology are also to be recommended. It may even be necessary to tailor such courses to the needs of these visitors to philosophy, showing how philosophical questions arise within their home disciplines, even though this might prove to be quite labour-intensive.

Finaily, it is to be recommended that the university become, if it is not already, a place of philosophical culture. The university consists of disciplines which 


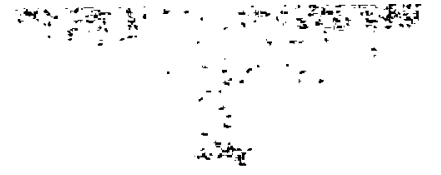

continually make knowledge claims, which inculcate methods, ontologies and values in the minds of their apprentices. There must be a generalised knowledge, and one which is more than what Newman would describe as a floating opinion, regarding the relative quality and nature of such claims, the intelligibility of the various ontologies, the validity and range of the methods, and above all a nuanced and adequate understanding of the values embodied in the disciplines and of the university itself. As university people we stand for certain values, which implies having made decisions which downgrade or exclude certain items, while vindicating others, as valuable. We must have a coherent, nuanced and convincing justification of those values, otherwise we will find ourselves dumb before our critics. Such a justification means not just providing an apology for the status quo, but looking systematically, carefully and critically at the values we espouse, and being willing both to change when this is shown to be necessary, and to enter into non-superficial dialogue with other sectors of society, such as government, and with society at large, conceming those values, thereby in turn placing values accepted in these sectors and in society under discussion and evaluation. We must encourage open debate, appealing thereby to the rationality of our partners, whom we must encourage also to put cherished opinions at risk. An inward-looking university does none of those things, and encourages rather the making of decisions by other than rational means. The voice or voices of the university must be heard in all matters of public concern, and this means not just having relevant expertise, but a viable and accurate, ethical and logical Weltanschaung, which includes a theory of what constitutes best practice in the art of decision-making. The dictum 'know thyself' is as relevant to organisations as it is to individuals.

\footnotetext{
I This forms the opening sentence of her essay "On "God" and "Good", reprinted in her collection Existentialists and Mystics; Writings on Philosophy and Literature. Peter Conradi, ed., (London: Chatto and Windus, 1997), pp. 337-362. The essay also appeared in The Sovereigny of Good. (London: Routledge, 1970).

2 This forms the first paragraph of Murdoch's essay 'The Idea of Perfection', Existentialists and Mysties, pp. 299-336; the essay also appears in The Sovereignty of Good.

${ }^{3}$ The thinker of this between par excellence is the contemporary lrish philosopher, William Desmond. See his major studies, Being and the Between. (Albany: SUNY, 1995), and Ethics and the Between. (Albany: SUNY, 2001).

4 For the present writer's interpretation of Hejdegger, see Thomas A. F. Kelly, Language antd Transcendence: A Study in the Philosophy of Martin Heidegger and Karl-Otto Apel. (Bern: Lang, 1994).

${ }^{5}$ For a more extended treatment of this theme, see the present writer's essay, "Towards an Ontology of Love', in Thomas A. F. Kelly and Philipp W. Rosemann, eds, Amor Amicitioe: On the Love that is Friendship. Essays in Medieval Thought and Beyond in Honor of the Rev. James McEvoy. (LeuvenParis-Dudley MA: Peeters, 2004), pp. 195-224.

${ }^{6}$ Alfred North Whitehead, Process and Reality. (Corrected Edition), David Ray Griffin and Donald W. Sherburne, eds, (New York and London: The Free Press, Collier Macmillan, 1978), p. 3.

${ }^{7}$ Some would maitteain that the violence inherent in such a would-be comprehensive world-view unfolded in history in the ever-descending evolution of Marxism into Marxist-Leninism, reaching its nadir in Stalinism and Maoism, growths which originally sprang up in Hegelian soil.

${ }^{8}$ Whitehead was well aware of the limitations of speculative philosophy. See Process and Realing, p. 13.

${ }^{9}$ If that sentence (what's true for me is true for me, and...) is true for me alone who utters it, then it isn't true absolutely, which means that truth is absolute and I am in error. So I must maintain that my utterance is true for all-which contradicts what is said in the utterance.
} 


\footnotetext{
${ }^{10}$ Needless to say, there can be merely divergent viewpoints, but these are vindicated as viewpointsand not mere delirium-by being capable of armulation in the direction of something more adequate.

"Existentialists and Mystics, p. 146. See also p. 131: 'Hegel is sometimes wrongly thought of as remote, airy, and metaphysical in the purely pejorative sense of that word. He could more justly be considered as the first great modern empiricist... What Hegel teaches us is that we should attempt to describe phenomena... he set about describing a vast quantity of human experience, experience of individuals and of societies... The Hegelian characteristic... is a non-dualistic patience with phenomena'. Emphasis in the original. This is a far cry from the tyrannical Hegel mentioned above. If Marx and his historical progeny are descendents of Hegel, they are not the only kind of progeny Hegel can beget.

${ }_{12}$ It is to be remembered that Descartes circulated the Meditations among scholars before the work's publication, and that he poblished their objections together with his replies. Descartes believed that it was necessary to entertain and reply to others' objections, which shows that some place for dialogue was allowed for hy him, despite his more overt, programmatic 'methodological solipsism'.

${ }^{13}$ See note 9 above.

14 John Henry Newman, An Essay in Aid of a Grammar of Assent. (London: Longmans, 1895), Chapter VII, Section 2, p. 318.

15 An Essay on the Development of Christion Doctrine: The Edition of 1845. Edited, and with an introduction by J. M. Cameron, (Harmondsworth: Penguin, 1974), p. 99.

16 Towards a Transformation of Philosophy. (London, Boston and Henley: Routledge \& Kegan Paul, 1980 ), p. 262. The essay referred to occupies pp. 225-300. Emphasis in the original.

${ }^{17}$ See our own investigation of these topics in Language, World and God: An Essay in Ontology. (Dublin: Columba, 1996).
} 